\title{
Cooperative contributions of Interferon regulatory factor 1 (IRF1) and IRF8 to interferon- $\gamma$-mediated cytotoxic effects on oligodendroglial progenitor cells
}

Makoto Horiuchi ${ }^{1,2}$, Aki Itoh ${ }^{1,2}$, David Pleasure ${ }^{1,2}$, Keiko Ozato ${ }^{3}$, Takayuki Itoh ${ }^{1,2^{*}}$

\begin{abstract}
Background: Administration of exogenous interferon- $\gamma$ (IFN $\gamma$ ) aggravates the symptoms of multiple sclerosis (MS), whereas interferon- $\beta$ (IFN $\beta$ ) is used for treatment of MS patients. We previously demonstrated that IFN $\gamma$ induces apoptosis of oligodendroglial progenitor cells (OPCs), suggesting that IFN $\gamma$ is more toxic to OPCs than IFN $\beta$. Thus we hypothesized that a difference in expression profiles between IFN $\gamma$-inducible and IFN $\beta$-inducible genes in OPCs would predict the genes responsible for IFNy-mediated cytotoxic effects on OPCs. We have tested this hypothesis particularly focusing on the interferon regulatory factors (IRFs) well-known transcription factors up-regulated by IFNs.

Methods: Highly pure primary rat OPC cultures were treated with IFN $\gamma$ and IFN $\beta$. Cell death and proliferation were assessed by MTT reduction, caspse-3-like proteinase activity, Annexin-V binding, mitochondrial membrane potential, and BrdU-incorporation. Induction of all nine IRFs was comprehensively compared by quantitative PCR between IFN $\gamma$-treated and IFN $\beta$-treated OPCs. IRFs more strongly induced by IFN $\gamma$ than by IFN $\beta$ were selected, and tested for their ability to induce OPC apoptosis by overexpression and by inhibition by dominant-negative proteins or small interference RNA either in the presence or absence of IFN .
\end{abstract}

Results: Unlike IFNy, IFN $\beta$ did not induce apoptosis of OPCs. Among nine IRFs, IRF1 and IRF8 were preferentially up-regulated by IFN $\gamma$. In contrast, IRF7 was more robustly induced by IFN $\beta$ than by IFN $\gamma$. Overexpressed IRF1 elicited apoptosis of OPCs, and a dominant negative IRF1 protein partially protected OPCs from IFN $\gamma$-induced apoptosis, indicating a substantial contribution of IRF1 to IFNy-induced OPC apoptosis. On the other hand, overexpression of IRF8 itself had only marginal proapoptotic effects. However, overexpressed IRF8 enhanced the IFN $\gamma$-induced cytotoxicity and the proapoptotic effect of overexpressed IRF1, and down-regulation of IRF8 by siRNA partially but significantly reduced preapoptotic cells after treatment with IFN $\gamma$, suggesting that IRF8 cooperatively enhances IFNy-induced OPC apoptosis.

Conclusions: This study has identified that IRF1 and IRF8 mediate IFN $\gamma$-signaling leading to OPC apoptosis. Therapies targeting at these transcription factors and their target genes could reduce IFN $\gamma$-induced OPC loss and thereby enhance remyelination in MS patients.

\footnotetext{
* Correspondence: takito@ucdavis.edu

${ }^{1}$ The Department of Neurology, University of California Davis, School of

Medicine, Sacramento, California, USA

Full list of author information is available at the end of the article
} 


\section{Background}

Persistent demyelination often follows recurrent inflammation in multiple sclerosis (MS), even though oligodendroglial progenitor cells (OPCs) are present in the adult CNS as a potential source of oligodendrocytes for remyelination after loss of myelin [1-3]. As a pathological mechanism underlying this remyelination failure, accumulating evidence indicates that interferon- $\gamma$ (IFN $\gamma$ ), the only type II IFN secreted into the lesions by infiltrating $\mathrm{T}$ helper $1\left(\mathrm{~T}_{\mathrm{H}} 1\right)$ cells and natural killer cells, induces cytotoxic effects on OPCs, and inhibits their differentiation, leading to failure in de novo myelination by OPCs [4-9]. We also demonstrated in our previous study that actively proliferating OPCs are far more susceptible to cytotoxic effects of IFN $\gamma$ than are postmitotic mature myelinating oligodendrocytes [10]. In contrast to IFN $\gamma$, interferon- $\beta$ (IFN $\beta$ ), a type I IFN, is used successfully to reduce relapse rates in relapsing remitting MS [11]. However, though IFN $\beta$ has minimal adverse effects on proliferation, migration and differentiation of oligodendrocytes in vitro [12,13], it does inhibit remyelination after cuprizone-induced demyelination in vivo [14]. Given the extensive overlap in type I and type II IFN signaling pathways, our goal in the present study was to determine what molecular mechanisms are responsible for the much greater OPC toxicity of IFN $\gamma$ than IFN $\beta$.

The janus kinase (JAK)/signal transducer and activator of transcription (STAT) pathway has been well-studied as a principal intracellular signaling pathway activated by IFNs (Reviewed in [15]). Binding of IFN $\gamma$ to the type II IFN receptor results in the rapid autophosphorylation and activation of the receptor-associated JAK1 and JAK2, which in turn activates cytoplasmic STAT1 by phosphorylation at Tyr 701. Activated STAT1 proteins form homodimers, which translocate into the nucleus, and initiate transcription by binding to a specific motif, known as the IFN $\gamma$-activated site (GAS), in the promoters of various IFN-stimulated genes (ISGs). IFN $\beta$ utilizes another receptor, the type I IFN receptor, associated with JAK1 and tyrosine kinase 2 (TYK2), and regulates formation of the heterotrimeric transcription complex, interferon-stimulated gene factor 3 (ISGF3), composed of the activated forms of STAT1 and STAT2, and IRF9/ISGF3 $\gamma$. ISGF3 recognizes the IFN-stimulated response element (ISRE) which is distinct from the GAS, and activates transcription of another set of ISGs. Although there is a substantial overlap between IFN $\beta$ inducible and IFN $\gamma$-inducible ISGs stemming from their common dependence on activation of STAT1 [16], we hypothesized that IFN $\gamma$-mediated cytotoxic effects on OPCs are attributable to ISGs which are differently induced in OPCs by IFN $\gamma$ than by IFN $\beta$.
As an example of the ISGs which are differently induced between IFN $\gamma$ and IFN $\beta$, we previously examined IFN-mediated transcriptional induction of major histocompatibility complex class II (MHC-II) molecules in the oligodendroglial lineage [17]. Surface expression of MHC-II becomes detectable in OPCs after treatment with IFN $\gamma$, whereas IFN $\beta$ fails to induce expression of MHC-II. Our results indicated that the distinct difference in transcriptional activation of interferon regulatory factor 1 (IRF1) between IFN $\gamma$ and IFN $\beta$ is attributed to the difference in subsequent MHC-II expression. Thus, IRF1 is also a promising example of the ISGs responsible for IFN $\gamma$-mediated cytotoxic effects in OPCs. In agreement with this idea, involvement of IRF1 in IFN $\gamma$ induced OPC apoptosis has recently been reported [18].

IRF1 was originally isolated as a transcriptional activator of the IFN $\beta$ gene in response to viral infection $[19,20]$. IRF1 and eight other subsequently identified factors share a highly-conserved amino-terminal DNA binding domain (DBD) with five conserved tryptophan repeats, and thereby constitute a family of transcription factors, termed the IRF family (Reviewed in [21-24]). The DBD forms a helix-turn-helix domain and recognizes similar, if not identical, DNA motifs containing the consensus IRF recognition sequence, 5'-AANNGAAA-3' [25]. IRF2, which shares the highly homologous DBD with IRF1, is considered a transcriptional repressor for IRF1-mediated transcription by competing for the same cis elements $[19,26,27]$. In addition, most of the members, except IRF1 and IRF2, have an IRF association domain (IAD) at the C-terminal region, through which they interact with other members or other transcription factors. Despite the possible functional overlap and interplay among members of the IRF protein family, however, there have been only a few studies on the IRF family members in the oligodendroglial lineage [28], particularly with respect to their roles in IFN $\gamma$-mediated and IFN $\beta$-mediated signaling [17]. In this study, using primary cultures of highly pure OPCs from rats, we performed a comprehensive analysis of all members of the IRF family in OPCs in response to IFN $\gamma$ and IFN $\beta$, and examined the synergistic roles for IRF1 and IRF8 (also known as interferon consensus sequence binding protein (ICSBP)), in IFN $\gamma$-induced OPC apoptosis.

\section{Methods \\ Reagents and chemicals}

All reagents and culture media used in this study were purchased from SIGMA (St. Louis, MO, USA) and Invitrogen (Carlsbad, CA, USA), respectively, except for the following products: Human recombinant fibroblast growth factor 2 and platelet-derived growth factor A 
homodimer were from R\&D systems (Minneapolis, $\mathrm{MN}$, USA); rabbit anti-IRF1 and anti-IRF2 antibodies were from Santa Cruz Biotechnology (Santa Cruz, CA, USA), and mouse anti-glyceraldehyde-3-phosphate dehydrogenase (GAPDH) antibodies were from Chemicon (Temecula, CA, USA). Rabbit anti-IRF8 antibody was produced by Ozato's laboratory. Small interfering RNA (siRNA) for IRF2 (siRNA ID: s220597), IRF8 (siRNA ID: s146232), and Negative control siRNA were from Ambion (Austin, TX, USA).

\section{Mixed glial culture}

Primary mixed glial cultures from rats were prepared as reported previously [29]. Briefly, whole brains were dissected from 0 to 2-day-old Lewis rats, and submerged in ice-cold Leibovitz's L-15 medium. Under a dissecting microscope, olfactory bulbs, cerebral cortices and hindbrains were removed. After cleaning off meninges and vessels including choroidal plexus, the remaining brain tissues were cut into small chunks with a 21 -gauge needle, and digested by $0.0625 \%(\mathrm{w} / \mathrm{v})$ trypsin in $\mathrm{Ca}^{2+}$ and $\mathrm{Mg}^{2+}$-free Hank's Balanced Salt Solution (HBSS) for $20 \mathrm{~min}$. Dissociated cells were obtained by passing the softened chunks through a $1 \mathrm{ml}$ pipette tip several times, and collected by centrifugation at $365 \mathrm{xg}$ for $5 \mathrm{~min}$. The cells were resuspended in minimum essential medium alpha containing $5 \%(\mathrm{v} / \mathrm{v})$ fetal bovine serum and $5 \%(\mathrm{v} / \mathrm{v})$ calf serum, and plated onto a $10 \mathrm{~cm}$ culture dish. One day after plating, attached cells (designated as passage 0 ) were washed with HBSS to remove serum, and thereafter maintained in the medium (GM), a 3:7 mixture (v:v) of B104 neuroblastoma-conditioned medium and the N1 medium (high glucose Dulbecco's modified Eagle's medium supplemented with $6 \mathrm{mM}_{\mathrm{L}}$-glutamine, $10 \mathrm{ng} / \mathrm{ml}$ biotin, $5 \mu \mathrm{g} / \mathrm{ml}$ insulin, $50 \mu \mathrm{g} / \mathrm{ml}$ apo-transferrin, $30 \mathrm{nM}$ sodium selenite, $20 \mathrm{nM}$ progesterone and $100 \mu \mathrm{M}$ putrescine as final concentrations). Cultures were fed with fresh GM medium every other day for approximately 5 days, at which time the proliferating glial cells were almost confluent.

\section{Immunopanning for purification of ${\mathrm{A} 2 \mathrm{BS}^{+}}^{+}$rat $\mathrm{OPCs}$}

The mixed glial cultures were washed with $\mathrm{Ca}^{2+}$ and $\mathrm{Mg}^{2+}$-free HBSS, suspended in the N1 medium containing $0.1 \%(\mathrm{w} / \mathrm{v}) \mathrm{BSA}$, and plated and incubated on negative immunopanning plates coated with RAN-2 antibody for $30 \mathrm{~min}$ at $37^{\circ} \mathrm{C}$ to exclude RAN-2-positive cells [29]. Following two rounds of this negative selection, nonadherent cells were transferred to the A2B5 positive panning plates. After the serial immunopanning, purified cultures contained more than $95 \%$ of OPCs which were A2B5-positive, O4-negative, and glial fibrillary acidic protein-negative.

\section{Immunocytochemistry}

Cells cultured on poly- ${ }^{-}$-lysine-coated coverslips were incubated with A2B5 hybridoma supernatants (undiluted) at room temperature for $30 \mathrm{~min}$. After washing with phosphate-buffered saline (PBS), cells were fixed with $4 \%$ paraformaldehyde at room temperature for $15 \mathrm{~min}$, and then permeabilized with $100 \%$ methanol at $-20^{\circ} \mathrm{C}$ for $15 \mathrm{~min}$. For IRF8 staining, cells were incubated with anti-IRF8 antibody diluted at 1:50 in PBS containing $5 \%$ normal goat serum and $0.03 \%$ Triton-X 100 at room temperature for $2 \mathrm{~h}$, after permeabilization by $100 \%$ methanol. After incubation with fluorophoreconjugated secondary antibodies (1:50, v:v) in PBS at room temperature for $30 \mathrm{~min}$, nuclei were counterstained with 4,6-diamidio-2-phenylindole $(0.5 \mu \mathrm{g} / \mathrm{ml})$ for $10 \mathrm{~min}$, and then the coverslips were mounted on slide glasses with VectorShield (Vector laboratory, Burlingame, CA, USA).

\section{Immunoblots}

Protein lysates were prepared in the lysis buffer as described previously [10]. Twenty $\mu \mathrm{g}$ of protein from each sample were size-fractioned by SDS-polyacrylamide gel electrophoresis, transferred onto a nitrocellulose membrane (Schleicher \& Schnell, Keene, NH, USA) and probed with primary antibodies for IRF1 (1:400, v:v) and IRF8 (1:5000, v:v) for $1 \mathrm{~h}$. Full range recombinant Rainbow Molecular Weight Markers (Amersham Biosciences, Piscataway, NJ, USA) were used as a reference for molecular sizes. Immunoreactive signals were detected by enhanced chemiluminescence according to the manufacture's protocol (Amersham Biosciences). Equal protein loading was confirmed by subsequent probing with the mouse monoclonal antibody against GAPDH in each experiment.

\section{Caspase activity assay}

Cells were homogenized in lysis buffer (100 mM HEPES; $10 \%(\mathrm{w} / \mathrm{v})$ sucrose; $0.1 \%(\mathrm{w} / \mathrm{v})$ 3-[(3-cholamidopropyl) dimethylammonio]-1-propanesulfonate; $10 \mathrm{mM}$ dithiothreitol; $1 \mathrm{mM}$ EDTA; $1 \mathrm{mM}$ phenylmethylsulfonyl fluoride, $2 \mu \mathrm{g} / \mathrm{ml}$ aprotinin; $1 \mu \mathrm{g} / \mathrm{ml}$ pepstatin; $5 \mu \mathrm{g} / \mathrm{ml}$ leupeptin) [30]. The protein lysates were stored at $-80^{\circ} \mathrm{C}$ until use as a 1:1 (v:v) mixture with glycerol. Caspase activity was measured by a fluorometric method; protein samples $(10 \mu \mathrm{g})$ were incubated with the fluorogenic substrate, acetyl-Asp-Glu-Val-Asp- $\alpha$-(4-methylcoumaryl-7-amide) $(12.5 \mu \mathrm{M})$ (Ac-DEVD-AMC, Peptides international, Luoisville, KY, USA) in $250 \mu \mathrm{l}$ of the lysis buffer, and cleavage of Ac-DEVD-AMC was monitored by a multiplate spectrofluoromater, Gemini EM (Molecular devices, Sunnyvale, CA, USA) for $60 \mathrm{~min}$ at $25^{\circ} \mathrm{C}$. The DEVD-cleavage activity was expressed as delta RFU (relative fluorescence unit) $/ \mu \mathrm{g}$ protein $/ \mathrm{h}$. 


\section{5-bromo-2'-deoxyuridine (BrdU)-incorporation assay}

OPCs cultured in $60 \mathrm{~mm}$ dishes were exposed to a $4 \mathrm{~h}$ BrdU pulse $(10 \mu \mathrm{M})$ just prior to harvesting. The trypsinized cells were collected in GM and resuspended in 1.5 $\mathrm{ml}$ PBS. After fixation by $70 \%(\mathrm{v} / \mathrm{v})$ ethanol at $-20^{\circ} \mathrm{C}$ for overnight, $5 \times 10^{4}$ cells were washed with $1 \mathrm{ml}$ of the washing buffer $(0.1 \%(\mathrm{w} / \mathrm{v}) \mathrm{BSA}$ in PBS), and denatured by resuspension in $2 \mathrm{~N} \mathrm{HCl}$ at room temperature for $20 \mathrm{~min}$. After resuspending once more in washing buffer, the cells were incubated in $0.1 \mathrm{M}$ sodium borate at room temperature for $2 \mathrm{~min}$ to neutralize any residual acid. Cells that had incorporated BrdU following incubation were identified by incubation with a fluorescein isothiocyanate (FITC)-conjugated mouse anti-BrdU monoclonal antibody at room temperature for $20 \mathrm{~min}$ in dilution buffer $(0.1 \%(\mathrm{w} / \mathrm{v})$ BSA, $0.5 \%(\mathrm{v} / \mathrm{v})$ Tween-20 in PBS) followed by another resuspension in washing buffer. The labeled cells were detected in the green (FL1) channel of a flow cytometer, CyAn-ADP (Dako cytomation, Carpinteria, CA). FITC-conjugated mouse monoclonal IgG1 was used as isotype control.

\section{MTT assay}

Cell viability was estimated by the enzymatic conversion of 3-(4,5-dimethylthiazol-2-yl)-2,5-diphenyltetrazolium bromide (MTT) to formazan crystals in live cells. Formazan was dissolved in dimethyl sulfoxide at $90 \mathrm{~min}$ after addition of MTT $(0.5 \mathrm{mg} / \mathrm{ml})$ to the culture medium, and quantified by a spectrophotometer or a microplate reader at $560 \mathrm{~nm}$.

\section{Annexin- $\mathrm{V}$ and propidium iodide binding assay}

The OPC cultures were maintained in $60 \mathrm{~mm}$ dishes and subjected to various experimental treatments. At 0 , 24 , and $48 \mathrm{~h}$ after these treatments, the culture medium containing detached dead cells was collected, and the attached cells were washed once with $2 \mathrm{ml}$ of $\mathrm{Ca}^{2+}$ and $\mathrm{Mg}^{2+}$-free HBSS. The attached cells were removed from the plate by exposure to $0.5 \mathrm{ml}$ of $0.05 \%$ trypsin at $37^{\circ} \mathrm{C}$ for $2 \mathrm{~min}$, suspended in $2 \mathrm{ml}$ of GM with $625 \mu \mathrm{g} / \mathrm{ml}$ trypsin inhibitor, and collected into a $15 \mathrm{ml}$ tube together with the saved medium and the $\mathrm{Ca}^{2+}$ and $\mathrm{Mg}^{2}$ ${ }^{+}$-free HBSS used for wash. After centrifuge at $520 \mathrm{xg}$ for $10 \mathrm{~min}$, the pellet was resuspended into $0.4 \mathrm{ml}$ of binding buffer (0.1 M HEPES, pH 7.4; $140 \mathrm{mM} \mathrm{NaCl}$; $2.5 \mathrm{mM} \mathrm{CaCl}_{2} ; 0.45 \%(\mathrm{w} / \mathrm{v})_{\mathrm{D}}$-glucose). Five $\mu \mathrm{l}$ of FITCconjugated annexin- $\mathrm{V}$ solution and propidium iodide (PI; $8 \mu \mathrm{g} / \mathrm{ml}$ at final concentration) were added into $0.1 \mathrm{ml}$ of the cell suspension. After incubation at room temperature for $15 \mathrm{~min}$ in the dark, $0.3 \mathrm{ml}$ of the binding buffer was added to the cell suspension. To determine the absolute number of cells in each preparation, Flow-Count ${ }^{\mathrm{TM}}$ fluorospheres were added at a concentration of 19 beads/ $\mu$ l just before flow cytometry by CyAn-
ADP (DakoCytomation, Carpinteria, CA, USA). Fluorescence of annexin-V-FITC and PI were detected in FL-1 and FL-4 channels, respectively. Gatings and data acquisition and analysis were carried out using Summit software (DakoCytomation) as described previously [10].

\section{Cell death and loss of mitochondrial membrane potential assay}

Rat OPCs cultured in 24-well plates were treated with the GM or the GM supplemented with IFN $\gamma$ for 12,18 , and $24 \mathrm{~h}$. Prior to collection, cells were incubated with tetramethylrhodamine ethyl ester (TMRE, $0.1 \mu \mathrm{M}$ ) at $37^{\circ} \mathrm{C}$ for $30 \mathrm{~min}$. Then, culture medium containing dead cells was collected, and cells were washed once with $0.5 \mathrm{ml}$ of the $\mathrm{Ca}^{2+}$ and $\mathrm{Mg}^{2+}$-free HBSS. Attached cells were removed with $150 \mu \mathrm{l}$ of $0.05 \%$ trypsin for $1 \mathrm{~min}$, suspended in $1 \mathrm{ml}$ of the GM, and collected into a $15-\mathrm{ml}$ tube together with the saved medium and the $\mathrm{Ca}^{2+}$ and $\mathrm{Mg}^{2+}$-free HBSS used for washing. After centrifugation with $1500 \mathrm{rpm}$ for $5 \mathrm{~min}$, the supernatant was aspirated and the pellet was kept on ice. Pellets were resuspended with $0.5 \mathrm{ml}$ PBS containing $5 \mu \mathrm{M}$ DAPI and $0.1 \%$ BSA immediately prior to analysis by flow cytometry employing a Cyan-ADP Flow Cytometer (DakoCytomation). Live and dead cell populations were gated as described previously [10], and TMRE and DAPI were detected in the FL-2 and the FL-6, respectively.

\section{Real-time PCR}

Real-time PCR analyses were performed by MX3005P (Stratagene, La Jolla, CA, USA) using TaqMan ${ }^{\circledR}$ Assayon-Demand $^{\mathrm{TM}}$ assay kits (assay nos.: Rn00561424_m1, Mm00515204_m1, Rn01764369_m1, Rn01435145_m1, Rn01500522_m1, Rn01762216_g1 and Rn01751474_m1 for detection of IRF1, IRF2, IRF3, IRF4, IRF5, IRF8 and interferon gamma induced GTPase (IGTP) cDNA, respectively) [17]. For detection of IRF6, IRF7, and IRF9 cDNA, each set of primers and a probe was obtained from Applied Biosystems as a Custom TaqMan ${ }^{\circledR}$ Gene Expression Assay, because the kits for these cDNA were not available at the time of these experiments. For standardization, GAPDH cDNA levels were quantified with TaqMan Rodent GAPDH Control Reagents according to the manufacturer's instructions, and the absolute cDNA amounts were expressed as ratios to GAPDH cDNA. We present representative data from at least two independent analyses for each mRNA.

\section{Plasmid construction}

For the forced expression vectors, the open reading frame of rat IRF1 or IRF8 was inserted in the pcDNA3.1 mammalian expression vector followed by the internal ribosome entry site (IRES) and humanized Renilla reniformis green fluorescent protein (hrGFP, Stratagene) in 
order to facilitate identification of transfected cells by flow cytometry or by fluorescence microscopy. The expression vector for the dominant-negative form of IRF1 (IRF1DN-hrGFP) and was constructed by inserting the coding sequence of truncated rat IRF1 (amino acids 1 to 144 ) into the pcDNA3.1 mammalian expression vector. The truncated IRF1 coding sequence was fused to hrGFP in frame with a spacer sequence, ProGly-Gly-Gly-Gly-Pro (P4GP) hinge, in order to facilitate identification of transfected cells and to evaluate the intracellular localization and stability of the dominant negative protein. For forced double expression of IRF1 and IRF8, the expression construct for IRF8 lacking hrGFP reporter (PCMV-IE-IRF8-pA) was prepared by inserting the open reading frame of rat IRF8 into pcDNA3.1.

\section{Transfection by electroporation}

Trypsinized OPCs $\left(2 \times 10^{6}\right)$ were resuspended in $100 \mu \mathrm{l}$ of N1 medium with $10 \mu \mathrm{g}$ plasmid DNA or $2 \mu \mathrm{M}$ siRNA, and put into a $2 \mathrm{~mm}$ cuvette. A square pulse with $110 \mathrm{mV}$ for $25 \mathrm{msec}$ was applied to the mixture of cells and plasmid DNA with BioRad GenePulser Xcell (BioRad, Hercules, CA, USA). Cells were resuspended into GM, plated on 24 well plates, and subjected to further experimental procedures.

\section{Statistical analysis}

Data are presented as mean \pm SD unless otherwise noted. Statistical significance was determined by twotailed ANOVA followed by Student-Newman-Keuls post hoc test.

\section{Results}

IFN $\beta$ is far less cytotoxic to OPCs than IFN $\gamma$

IFN $\gamma$ significantly reduced the viability of purified A2B5-positive OPCs to $32 \pm 5 \%$ of the controls at $48 \mathrm{~h}$ as reported in our prior study [10]. In contrast, IFN $\beta$ decreased the viability only to $91 \pm 8 \%$ of the controls at $1 \mathrm{kU} / \mathrm{ml}$, a concentration sufficient to exert maximum biological effects in various cell types [13,31,32] (Figure 1G). IFN $\beta$ failed to protect OPCs from IFN $\gamma$ induced cytotoxicity when IFN $\beta$ and IFN $\gamma$ were added simultaneously (Figure. 1G). IFN $\beta$ did not alter surface expression of A2B5 or the typical OPC morphology (Figure. 1A-F).

Cytotoxicity of IFN $\gamma$ to OPCs consists of increase in apoptosis and delay in G1/S transition of the cell cycle [10]. Double staining with Annexin-V-FITC and PI revealed that IFN $\beta$ did not increase numbers of preapoptotic and dead cells compared to the control OPC cultures, whereas preapoptotic cells became detectable from $24 \mathrm{hr}$, and dead cells were significantly increased
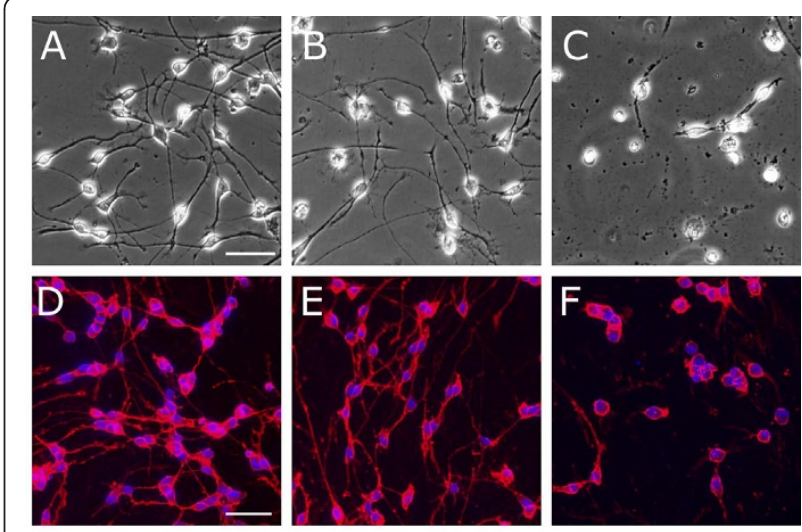

G

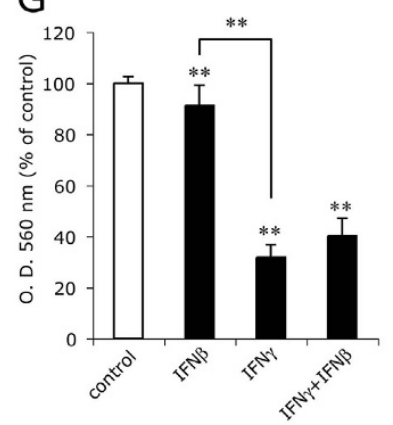

Figure 1 IFN $\beta$ is far less toxic to OPCs than IFN $\boldsymbol{\gamma}$. Phase-contrast images $(\mathbf{A}-\mathbf{C})$ and immunocytochemistry for A2B5 (D-F) of rat OPCs treated with GM alone (A, D), GM plus IFN $\beta(1 \mathrm{kU} / \mathrm{ml}) \mathbf{( B}, \mathbf{E})$ or $\mathrm{GM}$ plus IFNy (100 ng/ml) (C, F) for 48 h. G, Viability of OPCs cultured with GM (control), GM supplemented with IFN $\beta$ (IFN $\beta)$, IFN $\gamma($ IFN $\gamma)$, or both (IFN $\gamma+$ IFN $\beta$ ) was measured by MTT assay at $48 \mathrm{~h}$ after treatment. ${ }^{* *}$ Indicates $\mathrm{p}<0.01$ compared with control. ${ }^{* *}$ Indicates $p<0.01$ compared with control or in comparison between the two groups indicated.

at $48 \mathrm{~h}$ in the IFN $\gamma$-treated OPC cultures (Figure. 2A, B). Caspase-3-like protease activity was significantly induced by IFN $\gamma$ as early as $24 \mathrm{~h}$, but not by IFN $\beta$ even at $48 \mathrm{~h}$ (Figure. $2 \mathrm{C}$ ). These results indicated that, unlike IFN $\gamma$, IFN $\beta$ did not enhance OPC apoptosis.

This far less proapoptotic effect of IFN $\beta$ on OPCs was not a consequence of less equivalent biological activity of IFN $\beta$ at $1 \mathrm{kU} / \mathrm{ml}$ compared to IFN $\gamma$ at $100 \mathrm{ng} / \mathrm{ml}$. First, a higher concentration of IFN $\beta, 3 \mathrm{kU} / \mathrm{ml}$, also failed to induce caspase-3-like protease activity in OPCs (Figure. 2D). Second, as far as determined by transcriptional induction of IFN $\gamma$ induced GTPase (IGTP), IFN $\beta$ at $0.3 \mathrm{kU} / \mathrm{ml}$ or higher was sufficient to induce maximal levels of IGTP mRNA (Figure. 2E). Third, based on the standard anti-viral assay to measure the biological activities of IFNs [33], $100 \mathrm{ng} / \mathrm{ml}$ IFN $\gamma$ corresponds to approximately 0.1 to $1 \mathrm{kU} / \mathrm{ml}$, which is almost comparable to the biological unit of IFN $\beta$ used in this study. We therefore compared the effects of IFN $\gamma$ and IFN $\beta$ at 


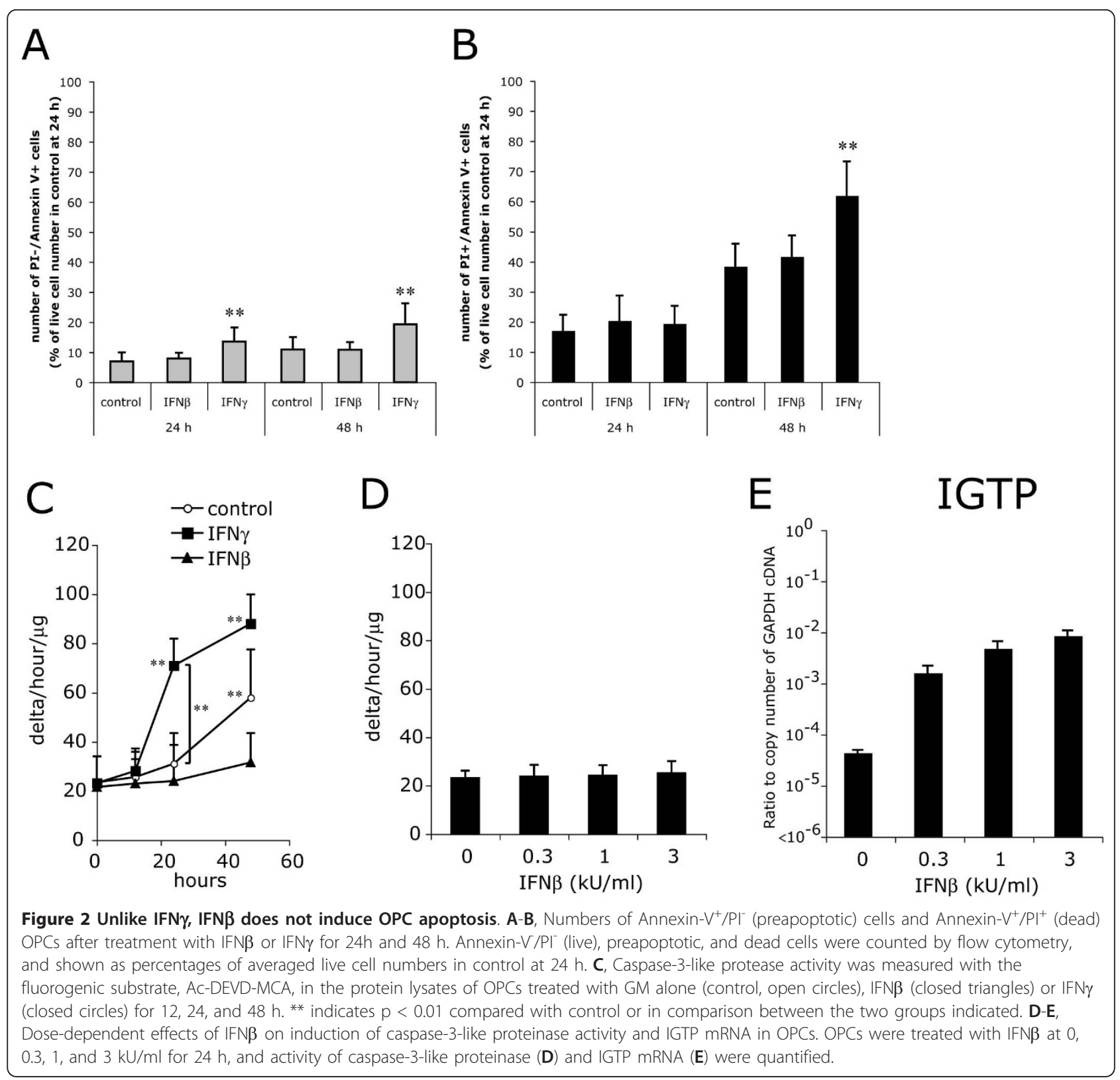

$100 \mathrm{ng} / \mathrm{ml}$ and $1 \mathrm{kU} / \mathrm{ml}$, respectively, in further experiments.

IFN $\gamma$ has been shown to inhibit cell cycle progression in OPCs as well [10]. Cells were exposed to a $4 \mathrm{~h} \mathrm{BrdU}$ pulse immediately prior to fixation at 24 and $48 \mathrm{~h}$ after treatments with IFN $\beta$ or IFN $\gamma$. The results confirmed that both IFN $\gamma$ and IFN $\beta$ significantly slowed progression of the cell cycle $(\mathrm{p}<0.01)$ at 24 and $48 \mathrm{~h}$. Percentages of BrdU-positive cells were significantly lower in the OPCs treated with IFN $\gamma$ than those treated with IFN $\beta$ at $48 \mathrm{~h}$, indicating that IFN $\beta$ did inhibit cell cycle progression in OPCs, but to a lesser extent than IFN $\gamma$ (Figure. 3).
Depolarization of the mitochondrial membrane potential precedes IFN $\gamma$-induced OPC apoptosis

Depolarization of the mitochondrial inner membrane is one of the earliest hallmarks of apoptosis in many cell types $[34,35]$. We identified preapoptotic OPCs with depolarized mitochondria in the IFN $\gamma$ - and IFN $\beta$-treated OPC cultures by live cell staining with both TMRE and DAPI followed by flow cytometry. The number of preapoptotic cells with depolarized mitochondria but retaining an intact plasma membrane (TMRE $/ \mathrm{DAPI}^{-}$cells) was significantly increased in OPC cultures treated with IFN $\gamma$ as early as $18 \mathrm{~h}$ after treatment, confirming that 


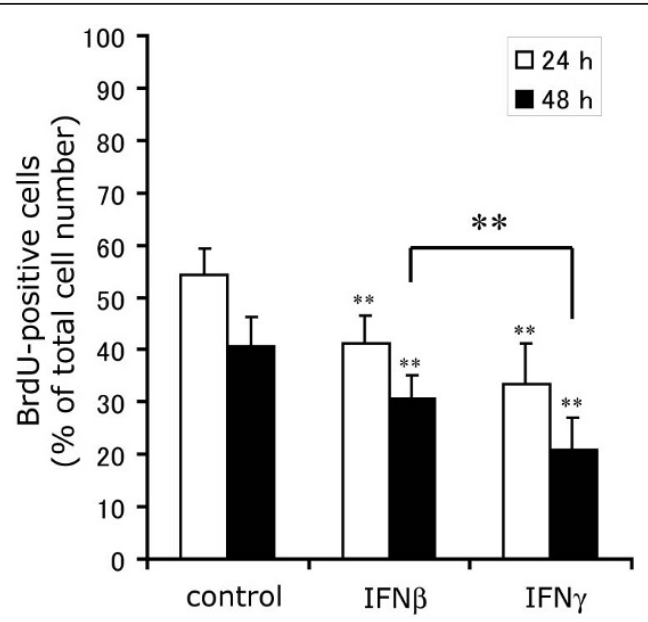

Figure 3 IFN $\beta$ inhibits progression of the cell cycle, though to a lesser extent than IFN $\gamma$. BrdU-incorporation of OPCs incubated with IFN $\beta(1 \mathrm{kU} / \mathrm{ml}$, IFN $\beta)$ or IFN $(100 \mathrm{ng} / \mathrm{ml}$, IFN $\gamma)$ for 24 (open bars) and $48 \mathrm{~h}$ (closed bars). OPCs were exposed to a $4 \mathrm{~h}-\mathrm{BrdU}$ pulse immediately before fixation. ${ }^{* *}$ Indicates $p<0.01$ compared with control or in comparison between the two groups indicated.

mitochondrial depolarization preceded IFN $\gamma$-induced OPC apoptosis. In good agreement with the results of the viability and caspase activity assays, however, preapoptotic OPCs did not increase in the cultures treated with IFN $\beta$ (Figure. 4).

IRF1 and IRF8 are preferentially up-regulated in OPCs treated with IFN $\gamma$ compared to those treated with IFN $\beta$ IFN $\gamma$ induces OPC apoptosis, while IFN $\beta$ does not. We hypothesized that, although IFN $\beta$ and IFN $\gamma$ transcriptionally up-regulate substantially overlapping ISGs [16], there must be some critical difference between IFN $\gamma$ inducible and IFN $\beta$-inducible gene sets that is responsible for IFN $\gamma$-induced apoptosis of OPCs. Among hundreds of ISGs, some members of the IRF protein family are immediate transcriptional targets of interferon-mediated JAK/STAT signaling, and subsequently control induction of downstream ISGs as transcription regulators [21-24]. Indeed, we previously demonstrated that IRF1 and IRF9 transcriptional kinetics differ between IFN $\gamma$-treated and IFN $\beta$-treated OPCs [17]. IFN $\gamma$ elicited a more than 70-fold sustained elevation of IRF1 mRNA from the basal levels in OPCs. In contrast, IFN $\beta$-mediated up-regulation of IRF1 mRNA was transient even in the continuous presence of IFN $\beta$, falling to less than one tenth of the sustained levels induced by IFN $\gamma$ at $24 \mathrm{~h}$. We extended this analysis to other members of the IRF protein family to obtain a comprehensive view of differential transcriptional regulation of all known IRFs in response to IFN $\gamma$ and IFN $\beta$, because at least some members are able to heterodimerize [36-38]. The quantitative PCR results demonstrated that members of the IRF protein family in OPCs could be classified into three groups in terms of their distinctive patterns of transcriptional induction by IFN $\gamma$ and IFN $\beta$; 1 ) IRF1 and IRF8 were preferentially up-regulated by IFN $\gamma$ compared with IFN $\beta$ (Figure. 5A), 2) IRF7 was preferentially up-regulated by IFN $\beta$ compared with IFN $\gamma$ (Figure. 5B), and 3) IRF2 to IRF6 and IRF9 were similarly regulated or not regulated by IFN $\gamma$ and IFN $\beta$, with the basal levels of the transcripts being IRF2 > IRF3 > IRF9 > IRF6 > IRF5 (Figure. 5C, The results of IRF5 are not shown.). IRF4 mRNA was below the detection limit in OPCs even in the presence of IFNs. We therefore focused on roles for IRF1 and IRF8 in IFN $\gamma$ induced apoptosis of OPCs in this study, because IRF1 mRNA and IRF8 mRNA were up-regulated within $1 \mathrm{hr}$ after addition of IFN $\gamma$, and remained at more than 10-fold higher levels than those induced by IFN $\beta$ until at least $24 \mathrm{~h}$ (Figure. 5D). Immunoblotting for IRF1 and IRF8 proteins also confirmed selective up-regulation of these proteins in the IFN $\gamma$-treated OPC cultures (Figure. 5E).

\section{IRF1 mediates IFN $\gamma$-induced OPC apoptosis}

We examined the effects of forced expression of either IRF1 or IRF8 on OPC viability. Since transient transfection of primary rat OPCs generally demonstrates limited efficiency, we used the dual expression constructs PCMV-IE-IRF1-IRES-hrGFP-pA and PCMV-IE-IRF8IRES-hrGFP-pA in order to discriminate transfected cells from untransfected cells with the aid of coexpressed hrGFP in the transfected cells. PCMV-IE-IRES-hrGFPpA was employed as control (Figure. 6). These dual expression constructs and the conventional cell death assay depending on the membrane-impermeable DNAbinding dye DAPI enabled us to count preapoptotic cells (TMRE-/DAPI ${ }^{-}$cells) in either hrGFP $^{+}$(transfected) or hrGFP' (untransfected) population by flow cytometry with the gating strategy shown in Figure. 7B. Overexpression of IRF1 significantly increased the number of preapoptotic cells in the transfected population at 6 and $24 \mathrm{~h}$ after transfection. On the other hand, overexpression of IRF8 resulted in a significant increase in $\mathrm{TMRE}^{-} / \mathrm{DAPI}^{-} /$ $\mathrm{hrGFP}^{+}$cells at $6 \mathrm{~h}$, although this effect was no longer observed at $24 \mathrm{~h}$. There was no significant increase in preapoptotic cells in the untransfected $\left(\mathrm{hrGFP}^{-}\right)$population, which could be used as an internal control, further validating these results (Figure. $7 \mathrm{C}$ ). Moreover, total live $\left(\mathrm{hrGFP}+\mathrm{DAPI}^{-}\right)$OPCs overexpressing IRF1 were reduced by approximately $50 \%$ from 6 to 24 h after transfection (Figure. 7D). These results indicate that upregulation of IRF1 protein is sufficient for activation of the apoptotic pathway in OPCs, but that up-regulation of IRF8 protein alone is not.

To further confirm the proapoptotic effects of IRF1 on OPCs, we overexpressed a fusion protein of the IRF1 DNA-binding domain and hrGFP as a dominant negative 


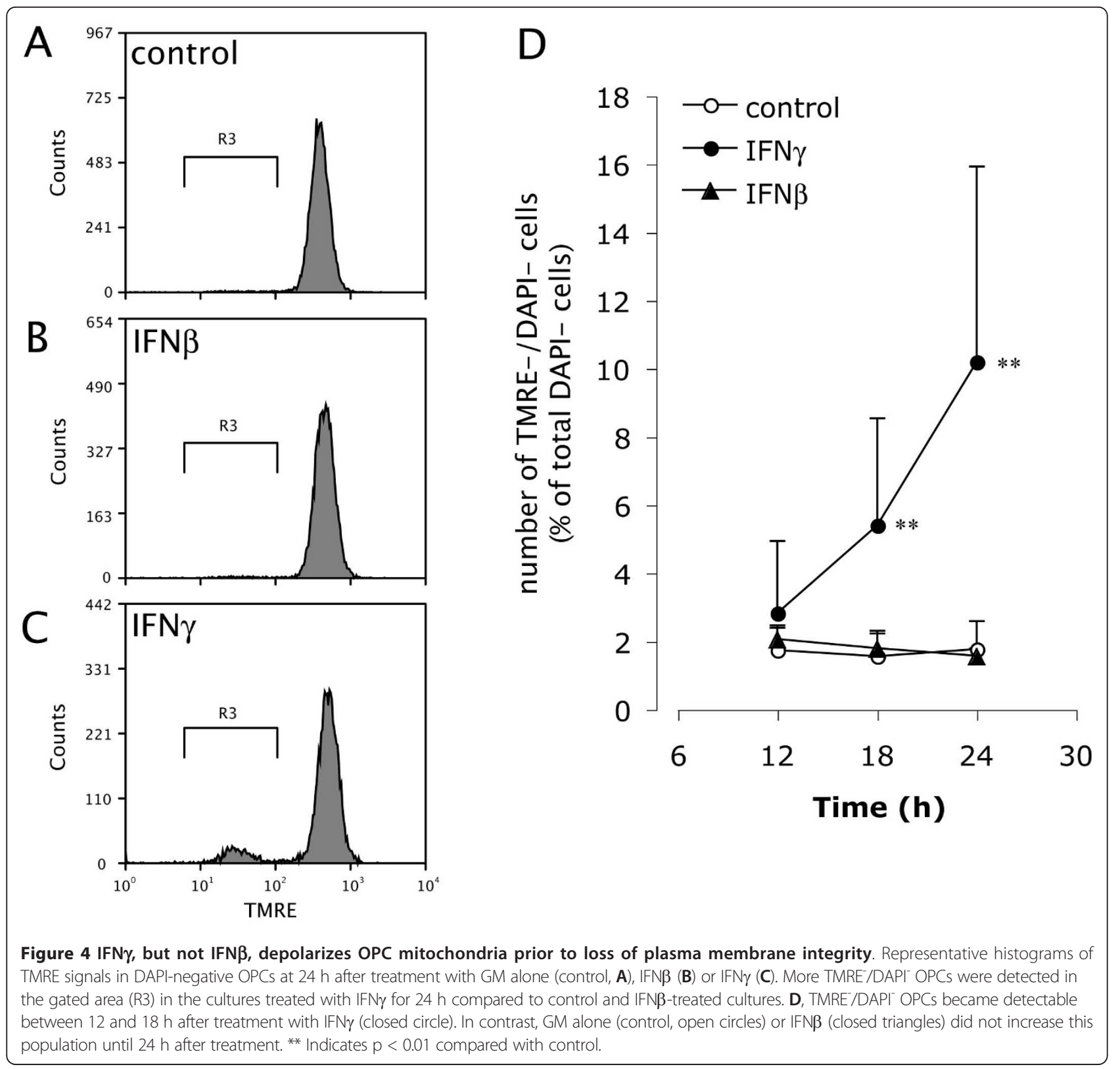

form of IRF1 (IRF1DN-hrGFP) in OPCs. OPCs were treated with IFN $\gamma$ at $24 \mathrm{~h}$ after transfection, and the number of preapoptotic (TMRE $/ \mathrm{DAPI}^{-}$) cells in either $\mathrm{hrGFP}^{+}$or hrGFP' population was measured at $24 \mathrm{~h}$ after addition of IFN $\gamma$ (Figure. 8A). Fluorescence microscopy demonstrated that the IRF1DN-hrGFP protein was localized in the nuclei of OPCs (Figure. 6C). Preapoptotic cells were partially but significantly reduced in the OPCs expressing IRF1DN-hrGFP at $24 \mathrm{~h}$ after addition of IFN $\gamma$, compared to the OPCs expressing hrGFP alone (Figure. 8B). These results confirmed that inhibition of functional IRF1 by IRF1DN-hrGFP protects OPCs from IFN $\gamma$-induced apoptosis, and that IRF1 is one of the ISGs that principally mediate IFN $\gamma$-induced OPC apoptosis.

\section{IRF8 enhances IFN $\gamma$-induced apoptosis of OPC}

Although overexpression of IRF8 itself was not sufficient to induce OPC apoptosis, it remained to be clarified whether overexpressed IRF8 enhanced IFN $\gamma$-induced OPC apoptosis. To examine this, OPCs were transfected with PCMV-IE-IRF8-IRES-hrGFP-pA, and then treated with IFN $\gamma$ at $24 \mathrm{~h}$ after transfection. Numbers of preapoptotic ( $\mathrm{TMRE}^{-} / \mathrm{DAPI}^{-}$) cells were significantly increased in IRF8 overexpressing OPCs, compared with 

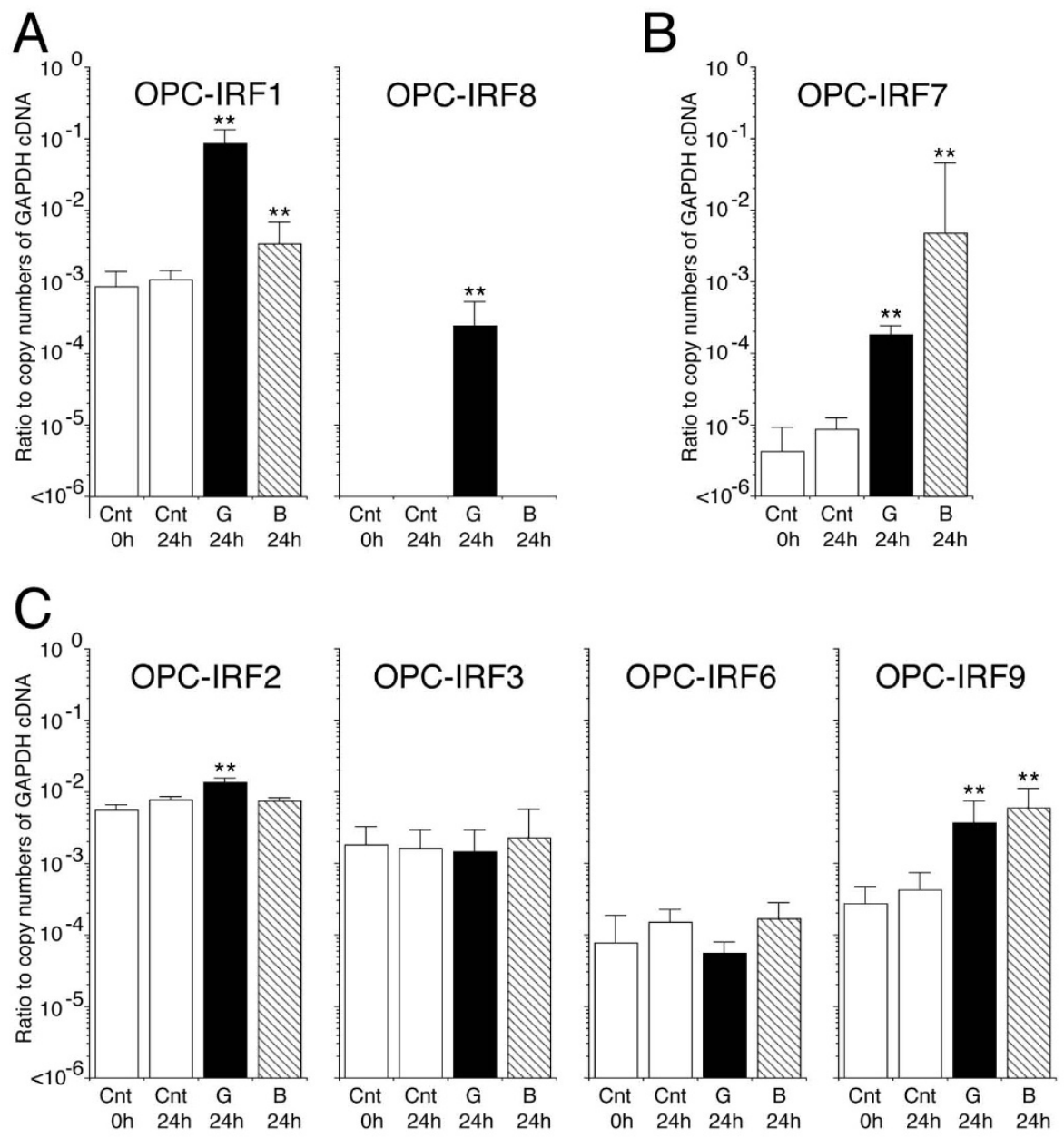

$\mathrm{D}$
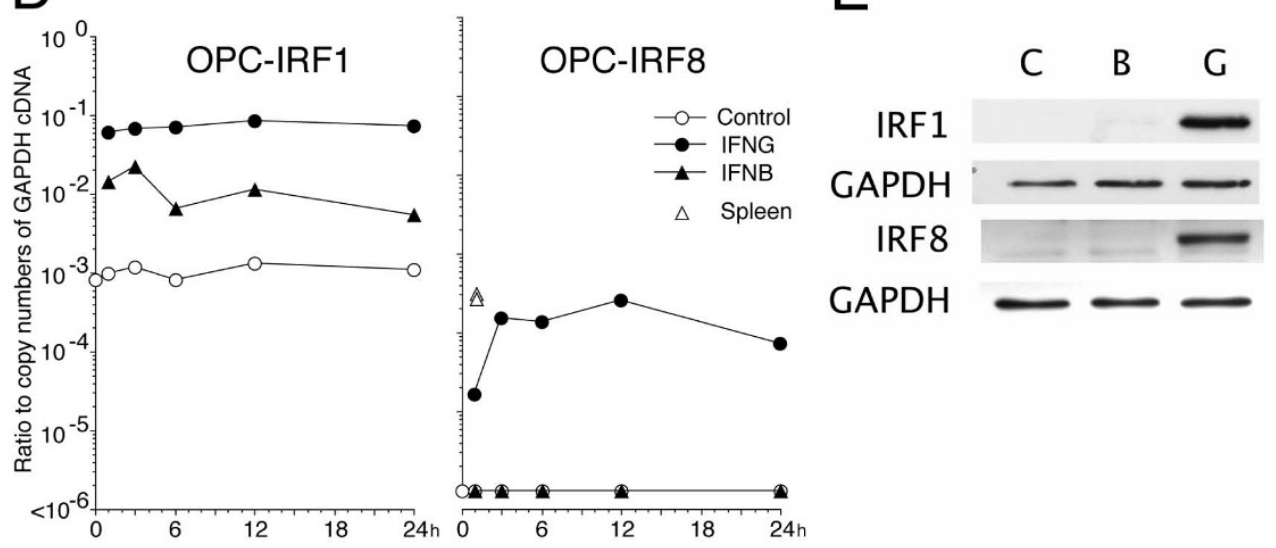

Figure 5 IRF1 and IRF8 are preferentially up-regulated in OPCs treated with IFN $\gamma$. A-C, Quantitative analysis of induction of IRF1, IRF2, IRF3, IRF6, IRF7, IRF8, and IRF9 mRNA in OPCs before (Cnt $0 \mathrm{~h}$ ) and at $24 \mathrm{~h}$ after incubation with IFN $(100 \mathrm{ng} / \mathrm{ml}, \mathrm{G} 24 \mathrm{~h}), \mathrm{IFN \beta}$ (1 kU/ml, B $24 \mathrm{~h})$, or medium alone (Cnt $24 \mathrm{~h}$ ). Each data point was from at least 3 independent experiments. Note that the data are plotted as ratios to copy numbers of GAPDH cDNA on a logarithmic scale. ${ }^{* *}$ Indicates $p<0.01$ compared with control at $24 \mathrm{~h}$ (Cnt $24 \mathrm{~h}$ ). D, IRF1 and IRF8 mRNA in OPCs were quantified by real-time PCR at 1, 3, 6, 12, and $24 \mathrm{~h}$ after addition of GM alone (control, open circle), IFNy (100 ng/ml, closed circle) or IFNß (1 kU/ml, closed triangle). For IRF8, basal IRF8 mRNA levels in the two RNA samples of spleen are shown as positive control (open triangles). At time 0, data from controls are only shown. E, Induction of IRF1 and IRF8 proteins in OPCs was examined at $24 \mathrm{~h}$ after treatment with IFN $\gamma$ and IFN $\beta$ by immunoblotting. 


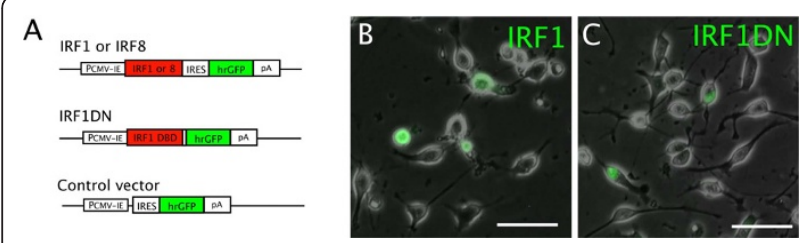

Figure 6 Expression constructs used in the study. A, PCMV-IE, immediate-early cytomegalovirus promoter; IRF1 DBD, IRF1 DNA binding domain; IRES, internal ribosome entry site; hrGFP,

humanized Renilla GFP; pA, poly adenylation signal sequence. B, Fluorescence signals of hrGFP in the transfected cells became detectable by microscopy as early as $6 \mathrm{~h}$ after transfection. C, Fluorescent imaging demonstrates that the IRF1DN-hrGFP fusion protein was localized in the nuclei of transfected OPCs.

those transfected with the control vector, at $24 \mathrm{~h}$ after addition of IFN $\gamma$ (Figure. 8B).

We further tested whether down-regulation of IRF8 by siRNA protected OPCs from IFN $\gamma$-induced apoptosis. Immunoblots after introduction of siRNA for IRF8 demonstrated that the employed siRNA only partially inhibited IRF8 induction by IFN $\gamma$ (Figure. 9B). The OPCs with reduced IRF8 protein levels to this extent showed no significant improvement in the viability of OPCs compared with those transfected with control siRNA at $48 \mathrm{~h}$ after treatment with IFN $\gamma$ (Figure. 9C). Nevertheless, the number of $\mathrm{TMRE}^{-} / \mathrm{DAPI}^{-}$preapoptotic OPCs was partially but significantly decreased in the cultures transfected with IRF8 siRNA than that in the control cultures at $24 \mathrm{~h}$ after treatment with IFN $\gamma$ (Figure. 9D).

Furthermore, we examined whether IRF8 enhances the proapoptotic effects of overexpressed IRF1 in OPCs in the absence of IFN $\gamma$. OPCs were co-transfected with the IRF1 expression construct with hrGFP reporter (PCMVIE-IRF1-IRES-hrGFP-pA) and an IRF8 expression construct without hrGFP reporter (PCMV-IE-IRF8-pA) by electroporation to facilitate identification of double transfected cells (Figure. 10). As far as we could determine by immunocytochemistry, $96 \pm 4 \%(n=3)$ of $\mathrm{hrGFP}^{+}$cells were positive for IRF8 immunoreactivity, and $85 \pm 5 \%(\mathrm{n}=3)$ of $\mathrm{IRF}^{+}$cells were $\mathrm{hrGFP}^{+}$at $6 \mathrm{~h}$ after transfection, confirming that virtually all hrGFP ${ }^{+}$ cells expressed both IRF1 and IRF8 after co-transfection. When both IRF8 and IRF1 were overexpressed in OPCs (IRF1+IRF8), preapoptotic (TMRE /DAPI ${ }^{-}$) cells were significantly more than those in the OPCs overexpressing IRF1 alone (IRF1+empty) (Figure. 10B), although there was no statistical significance in reduction of live transfected cells $\left(\right.$ hrGFP ${ }^{+}$) between the IRF1+empty and IRF1+IRF8 groups at $24 \mathrm{~h}$ after transfection (Figure 10C). These results indicated that overexpressed IRF8 protein directly enhances the proapoptotic effects of IRF1 in OPCs even in the absence of IFN $\gamma$.

\section{Discussion}

Proapoptotic effects of IFN $\gamma$ and at most minimal cytotoxic effects of IFN $\beta$ on OPCs have been reported previously $[4-9,12,13]$. In the present study, however, we have directly compared effects of IFN $\gamma$ and IFN $\beta$ on OPCs in the same in vitro condition, and confirmed a substantial difference in proapoptotic effects between the two IFNs. Furthermore, IFN $\beta$ was not protective against IFN $\gamma$-induced OPC apoptosis, despite several prior reports that IFN $\beta$ antagonizes IFN $\gamma$ signaling [39-43]. As far as we could determine by transcriptional induction of IRF1, simultaneous application of IFN $\beta$ failed to reduce IFN $\gamma$-mediated robust induction of IRF1 [17]. Although the mechanisms underlying the beneficial therapeutic effects of IFN $\beta$ on relapsing-remitting MS are still largely unknown, recent studies have indicated that IFN $\beta$ and type I IFN receptor-mediated signaling limit CNS autoimmunity by regulating innate immune responses in peripheral tissues $[44,45]$ and the production and properties of $\mathrm{T}_{\mathrm{H}} 17$ cells, a pathogenic $\mathrm{T}$ helper subset largely responsible for CNS autoimmunity [46]. Despite the beneficial effects of IFN $\beta$ which is further ensured by far less cytotoxicity of IFN $\beta$ to OPCs, we observed that IFN $\beta$ did inhibit the cell cycle in OPCs, though to a lesser extent than IFN $\gamma$. It is thus conceivable that, as demonstrated by Trebst et al.[14], IFN $\beta$ attenuates the endogenous capability for remyelination, which is presumably masked by its profound beneficial effects on the immune system.

Based on the marked difference in proapoptotic effects between IFN $\gamma$ and IFN $\beta$ on OPCs, our next aim in this study was to identify those ISGs responsible for IFN $\gamma$ mediated OPC apoptosis. IFN $\gamma$ induces robust and sustained elevation of IRF1, whereas IFN $\beta$ elicits only a transient elevation of IRF1, which ends up being undetectable at the protein level at $24 \mathrm{~h}$ after treatment, indicating that IRF1 is a candidate for such an ISG [17]. In support of this, Balabanov's group has recently reported that, using a lentiviral expression system, down-regulation of IRF1 by IRF1 shRNA partially protected against IFN $\gamma$-induced OPC apoptosis, and that forced expression of IRF1 reduced the viability of OPCs [18]. We employed a different forced expression system and a dominant negative approach in this study, and confirmed significant involvement of IRF1 in IFN $\gamma$-mediated $\mathrm{OPC}$ apoptosis. We further provided direct evidence for activation of the mitochondrial apoptotic pathway by overexpression of IRF1 alone. Notably, however, both approaches used in our study and the study by Balabanov's group to down-regulate IRF1-mediated transcription failed to completely inhibit IFN $\gamma$-mediated apoptotic events, suggesting possible functional redundancy of the ISGs involved in IFN $\gamma$-mediated 
A

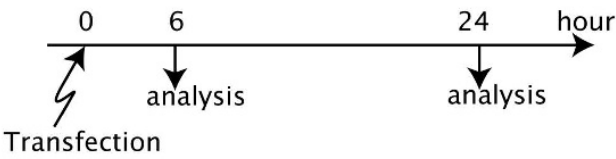

B
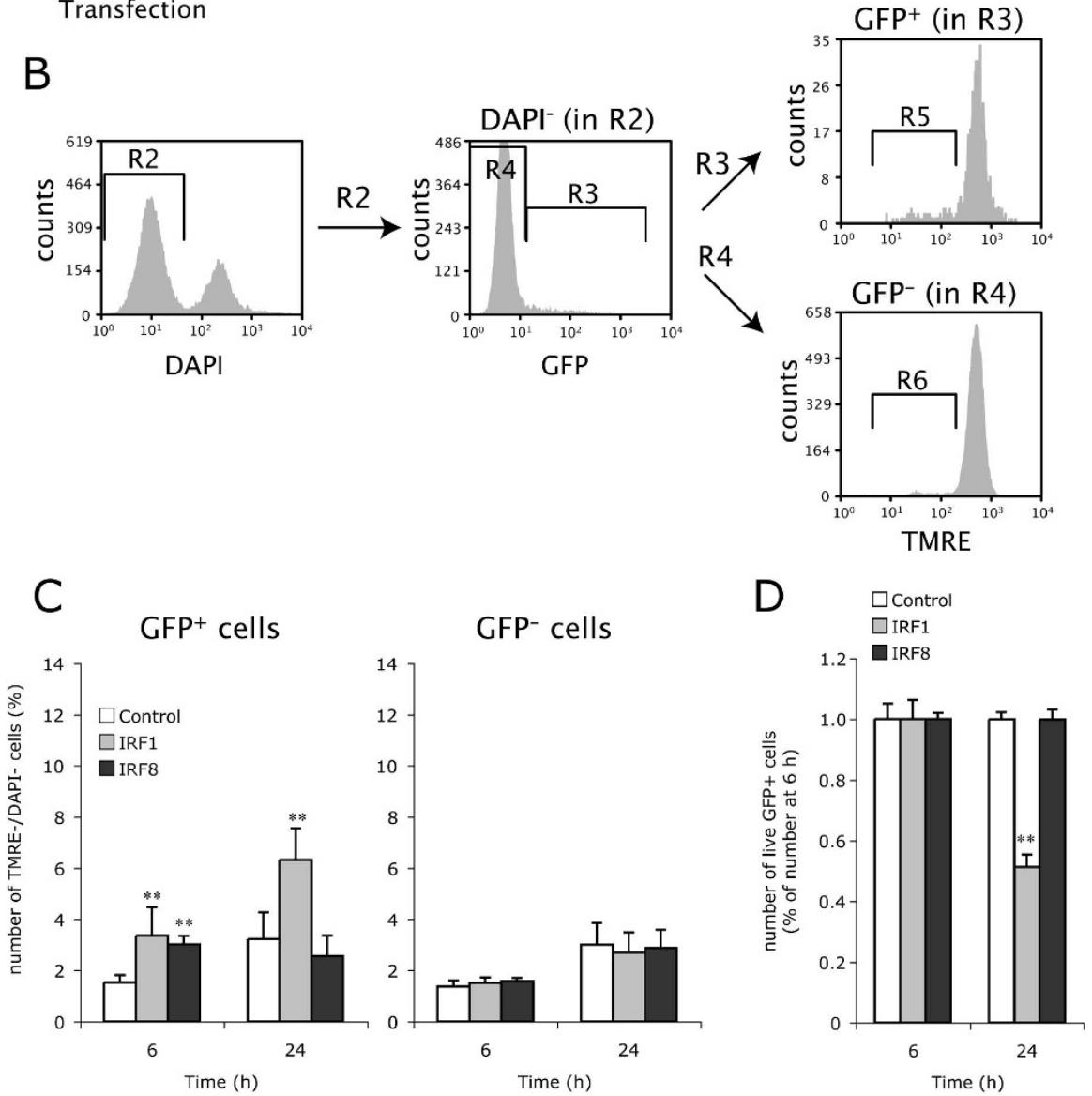

$E$

IRF1-GFP
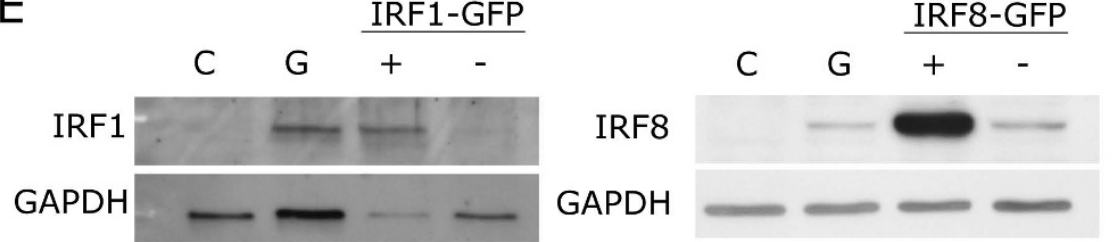

Figure 7 Overexpressed IRF1 induces OPC apoptosis, whereas overexpressed IRF8 does not. A, OPCs were transfected with the control vector (PCMV-IE-IRES-hrGFP-pA), the expression construct of rat IRF1 (PCMV-IE-IRF1-IRES-hrGFP-pA), or the expression construct of rat IRF8 (PCMVIE-IRF8-IRES-hrGFP-pA) by electroporation. These OPCs were incubated with TMRE and DAPI at 6 and $24 \mathrm{~h}$ after transfection and analyzed by flow cytometry. B, Representative gating scheme of flow cytometric analysis of preapoptotic (TMRE-/DAPI) OPCs in the transfected (hrGFP+) and untransfected (hrGFP) populations at $24 \mathrm{~h}$ after transfection with the IRF1 expression construct. Live cells negative for DAPI in the R2 gate were separated into hrGFP ${ }^{+}$(R3) and hrGFP - (R4) cells. Preapoptotic OPCs were then counted in the R5 and R6 gated areas in hrGFP ${ }^{+}$(R3) and hrGFP ${ }^{-}$(R4) populations, respectively. C, Number of preapoptotic (TMRE/DAPI) OPCs in transfected (hrGFP') and untransfected (hrGFP) populations at 6 and $24 \mathrm{~h}$ after transfection with the control vector, IRF1 expression construct or IRF8 expression construct. D, Reduction in live transfected cells (DAPI//hrGFP ${ }^{+}$) at $24 \mathrm{~h}$ in the cultures transfected with the control vector, IRF1 expression construct or IRF8 expression construct. Due to the different transfection efficiencies among the expression constructs, percentages of live transfected (DAPI/hrGFP') cells in total live (DAPI) cells were calculated in each condition, and are shown as fold changes of the calculated percentages at $6 \mathrm{~h}$ after transfection. ${ }^{* *}$ Indicates $p<0.01(n=9)$. E, Overexpressed IRF1 and IRF8 were verified by immunoblotting. GFP-positive cell populations in OPC cultures transfected with the expression constructs of rat IRF1 (IRF1-GFP') or IRF8 (IRF8-GFP ${ }^{+}$) were separated from GFP-negative cell populations (IRF1-GFP- and IRF8-GFP) with a cell sorter, and subjected to immunoblotting for IRF1 and IRF8, respectively. Untransfected OPCs cultured with medium alone (C), and medium containing IFN $(100 \mathrm{ng} / \mathrm{ml}$, G) were used as negative and positive controls, respectively. 


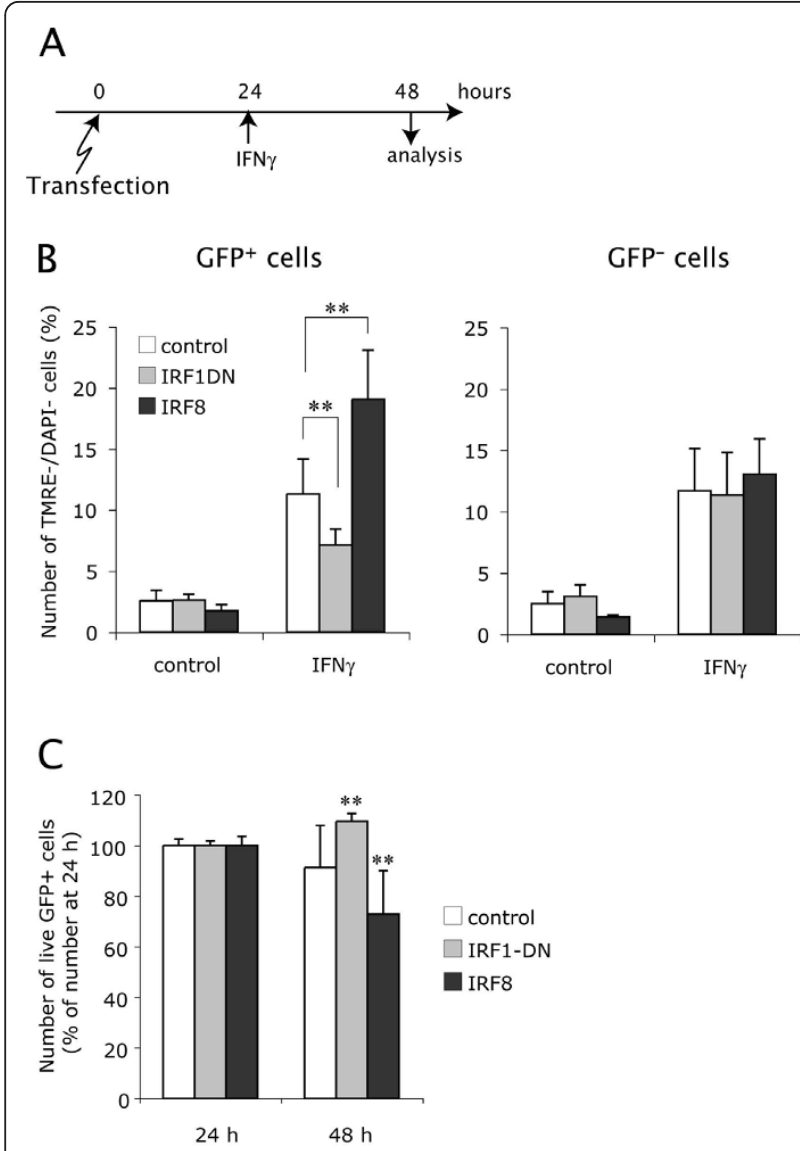

Figure 8 Effects of overexpressed dominant-negative IRF1 and overexpressed IRF8 on IFN $\gamma$-induced OPC apoptosis. A, OPCS were transfected by electroporation with the control vector (PCMVIE-IRES-hrGFP-pA), the expression construct of a dominant-negative form of IRF1 (IRF1DN-hrGFP) which is a fusion protein of IRF1 DNAbinding domain (IRF1DBD) and hrGFP (PCMV-IE-IRF1DBD/hrGFP-pA), and the expression construct of rat IRF8 (PCMV-IE-IRF8-IRES-hrGFPpA). Cells were cultured with GM for $24 \mathrm{~h}$ after transfection, and then treated with GM alone (control) or GM plus IFNy (100 ng/ml). At $24 \mathrm{~h}$ after treatments, cells were stained with TMRE and DAPI, and analyzed by flow cytometry as in Figure. 7. B, Number of preapoptotic (TMRE-/DAPI) OPCs in the cultures subjected to electroporation with the control vector or the IRF1DN expression construct at $24 \mathrm{~h}$ after treatment with IFN $(100 \mathrm{ng} / \mathrm{ml})$. Transfected (hrGFP ${ }^{+}$) and untransfected (hrGFP') populations were analyzed separately, using the same gatings as in Figure. 7. C, Number of live transfected cells (DAPI//hrGFP ${ }^{+}$) in the cultures transfected with the control vector, IRF1DN expression construct or IRF8 expression construct after a $24 \mathrm{~h}$ IFNy-treatment (48 h after transfection). Percentages of $\mathrm{DAPl}^{-} / \mathrm{hrGFP}^{+}$cells in total live (DAPl') cells were calculated in each condition, and are shown as fold changes of the percentages just before addition of IFN $(24 \mathrm{~h}$ after transfection). Note that the same percentages of transfected $\left(\mathrm{hrGFP}^{+}\right)$and untransfected (hrGFP) OPC populations died during $24 \mathrm{~h}$ after addition of IFNy in the control group, whereas less and more transfected OPCs were dead in the IRF1-DN and IRF8 groups, respectively. ${ }^{*}$ Indicates $p<0.01$ in comparison with the corresponding data at $24 \mathrm{~h}(\mathrm{n}=9)$. transcriptional activation leading to apoptosis of OPCs. Given the structural and functional similarity among members of the IRF family and their known interactions, transcriptional activity of IRF1 is likely to be modified or compensated by the other members of the IRF protein family.

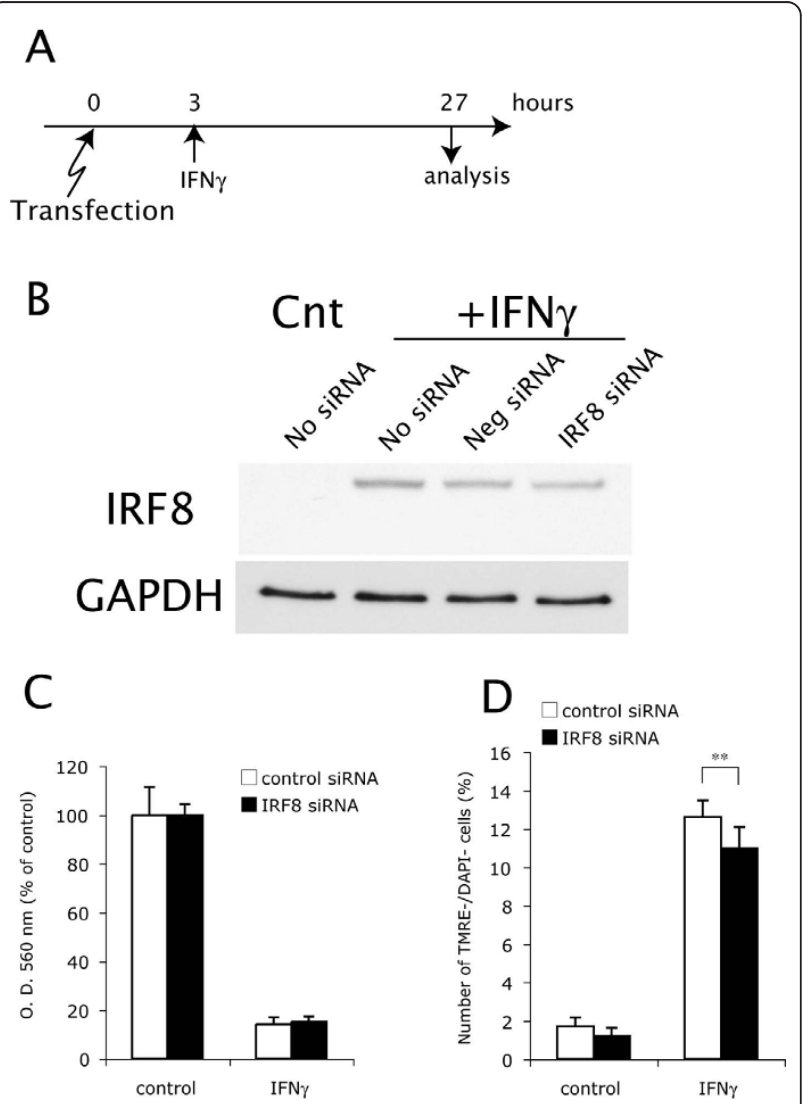

Figure 9 Selective down-regulation of IRF8 by siRNA protects OPCs from IFN $\gamma$-induced OPC apoptosis. A, OPCs were transfected by electroporation with IRF8 siRNA and negative conrol siRNA. Cells were cultured with GM for $3 \mathrm{~h}$ after transfection, and then treated with GM alone (control) or GM plus IFNy (100 ng/ml). At 24 or $48 \mathrm{~h}$ after treatments, cells were subjected to western blotting. MTT assay, or stained with TMRE and DAPI followed by the flow cytometric analysis as in Figure. 7. B, Protein levels of IRF8 in the OPCs transfected with negative control siRNA (Neg siRNA) or IRF8 siRNA were examined by immunoblotting at $24 \mathrm{~h}$ after addition of IFN $(+\mathrm{IFN} \gamma, 100 \mathrm{ng} / \mathrm{ml})$. The untransfected OPCs (No siRNA) treated with IFN (+IFN $\gamma, 100 \mathrm{ng} /$ $\mathrm{ml}$ ) or medium alone (C) for $24 \mathrm{~h}$ were used as positive and negative control for IRF1 expression, respectively. B, Viability of the OPCs transfected with negative control siRNA (control siRNA, open bar) or IRF8 siRNA (closed bar) was measured by MTT assay at $48 \mathrm{~h}$ after treatment with GM alone (control) or GM plus IFNy (100 ng/ml). C, Number of preapoptotic (TMRE/DAPI) OPCs in the cultures subjected to electroporation with negative control siRNA (control siRNA, open bar) or IRF8 siRNA (closed bar) at $24 \mathrm{~h}$ after treatment with IFN $\gamma$ $(100 \mathrm{ng} / \mathrm{ml}) .{ }^{* *}$ Indicates $\mathrm{p}<0.01(\mathrm{n}=9)$. 


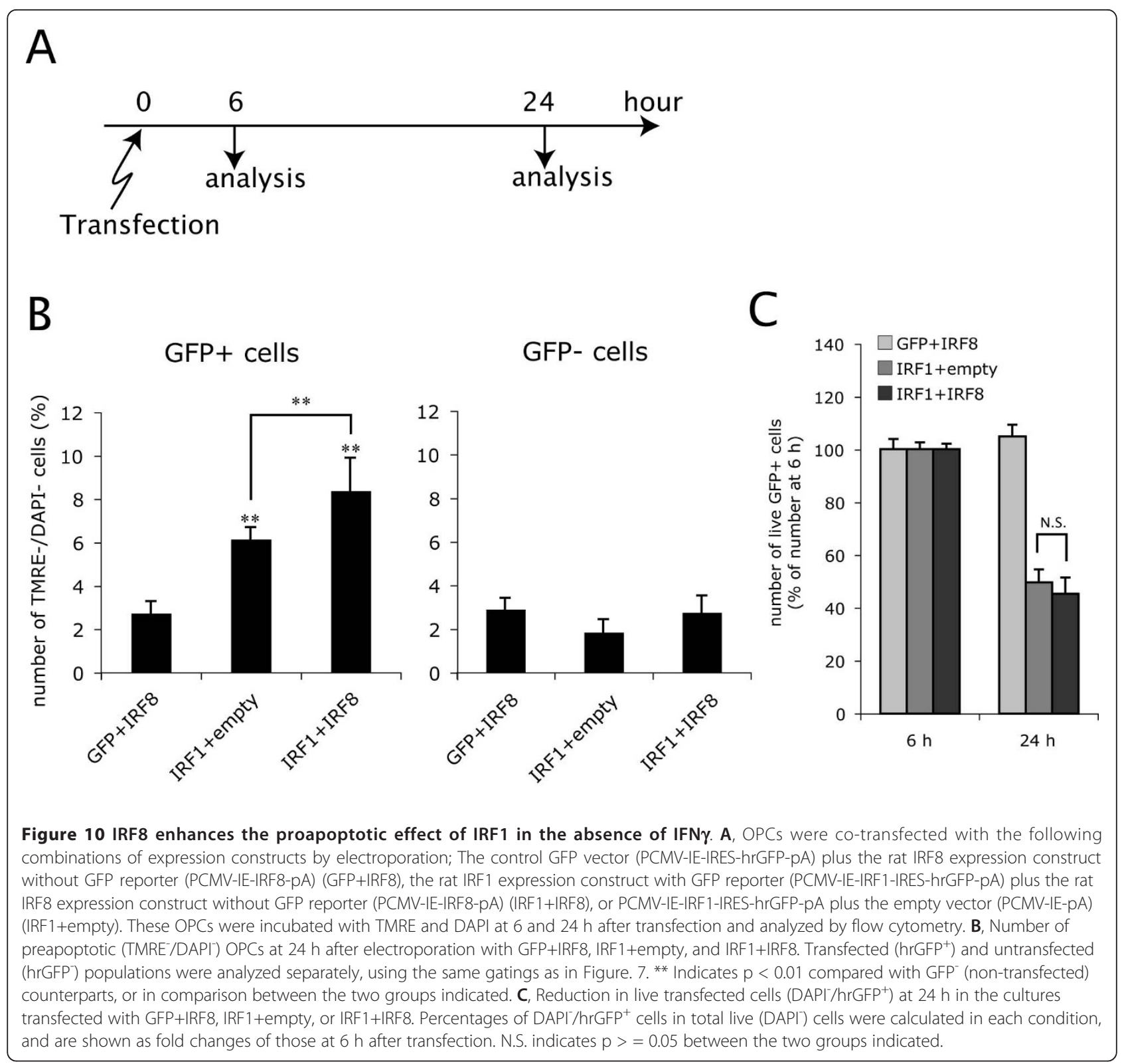

In an effort to obtain a comprehensive expression profile of the IRF family in OPCs stimulated by either IFN $\gamma$ or IFN $\beta$, we found that IRF8 was also up-regulated by IFN $\gamma$ but not by IFN $\beta$. IRF8 was originally identified as a protein that binds to the ISRE in the promoter region of the MHC class I gene H-2LD [47], and was believed to be expressed exclusively in the hematopoietic lineage (Reviewed in [48]). Our result indicates that OPCs are also capable of expressing IRF8 in response to IFN $\gamma$. In contrast to overexpression of IRF1, however, overexpression of IRF8 alone resulted in only transient depolarization of the mitochondrial membrane in OPCs, but failed to reduce their viability. More importantly, despite this weak proapoptotic effect of overexpressed IRF8 itself, it significantly enhanced the IFN $\gamma$-induced apoptosis and proapoptotic effect of overexpressed IRF1 in OPCs even in the absence of IFN $\gamma$. Unlike other IRF members, IRF8 is capable of binding to the target DNA motif only following association with IRF1, IRF2 or non-IRF transcription factors such as PU.1 $[36,49]$. As an example, IRF8 and IRF1 synergistically induce several genes, such as IL-12 and iNOS [50,51], in activated macrophages. A study from Ozato's group also demonstrated that IRF8 induced by activated STAT1 forms a multiprotein transcriptional complex with other nuclear proteins, which binds to GAS, and, in turn, potentiates transcriptional 
activation of the ISGs in a GAS-dependent manner [52]. Therefore, it is conceivable that, although IRF8 alone is not sufficient to activate the apoptogenic cascade in OPCs, IRF8 enhances IFN $\gamma$-induced OPC apoptosis by interacting with other transcription factors activated by IFN $\gamma$. Indeed, IRF8 is known to function as a proapoptotic transcription factor like IRF1. IRF8-deficient mice are characterized by a myeloproliferative phenotype resulting in a syndrome similar to human chronic myelogenous leukemia [53]. This oncogenic phenotype is attributable to cytokine hypersensitivity and apoptosis resistance of IRF8 deficient myeloid progenitor cells [54]. During differentiation of the myeloid lineage, IRF8 down regulates anti-apoptotic genes such as $\mathrm{Bcl}-\mathrm{X}_{\mathrm{L}}$, one of anti-apoptotic member of the Bcl-2 family, and PTPN13, which encodes an inhibitor of Fas-mediated apoptosis $[55,56]$. The anti-oncogenic roles of IRF8 are associated with its proapoptotic function in the other types of tumors as well. In colon carcinoma cells, IRF8 induced by IFN $\gamma$ sensitizes them to Fas-mediated apoptosis, but the silencing of the IRF8 gene by methylation of its promoter region renders them resistance to IFN $\gamma$ mediated apoptosis [57].

Reduction of IRF8 by siRNA failed to enhance viability of OPCs after treatment with IFN $\gamma$, although it partially but significantly decreased the number of preapoptotic cells. However, we still could not rule out a contribution of the endogenous IRF8 in the IFN $\gamma$-induced OPC apoptosis, because the transfection of the IRF8 siRNA resulted in only a partial suppression against the robust IRF8 induction by IFN $\gamma$. Together, these results support the notion that endogenous IRF8 positively regulates the IFN $\gamma$-induced OPC apoptosis depending on its induced dosage.

We previously demonstrated that, unlike OPCs, mature myelin-producing oligodendrocytes were totally resistant to IFN $\gamma$-induced apoptosis [10]. Nevertheless, IRF1 was similarly induced by IFN $\gamma$ in mature oligodendrocytes compared with OPCs $[10,17]$. We also confirmed that IFN $\gamma$ induced IRF8 mRNA at similar levels in both OPCs and mature oligodendrocytes (Data not shown.). These results indicate that IRF1mediated transcriptional activations may be necessary to activate the apoptotic cascade in OPCs, but are not sufficient. We speculate that differences in cellular context between OPCs and mature oligodendrocytes such as activities of ERK signaling are the other necessary components for IFN $\gamma$-induced OPC apoptosis as well $[10,58,59]$.

\section{Conclusions}

Conclusions from this study are summarized as follows. First, unlike IFN $\gamma$, IFN $\beta$ is far less capable of inducing
OPC apoptosis. Second, our comprehensive analysis of the IRF family members in IFN $\gamma$ - and IFN $\beta$-treated OPCs identified that IRF1 and IRF8 are preferentially up-regulated by IFN $\gamma$. Third, functional analyses of IRF1 and IRF8 revealed that not only IRF1 but also IRF8 contribute to the IFN $\gamma$-mediated OPC apoptosis. This finding will help us to identify downstream genes involved in OPC apoptosis. These transcription factors and their downstream target genes could be potential therapeutic targets to enhance remyelination in MS.

\section{Acknowledgements}

This work was supported by Research Grant of Shriners Hospitals for Children (No. 85400 to TI), Research fellowships of Shriners Hospitals for Children (to Al and MH) and US National Institute of Health grant NS025044 (to DP and TI).

\section{Author details}

'The Department of Neurology, University of California Davis, School of Medicine, Sacramento, California, USA. ${ }^{2}$ The Institute for Pediatric Regenerative Medicine, Shriners Hospitals for Children Northern California, Sacramento, California, USA. ${ }^{3}$ The Laboratory of Molecular Growth Regulation, Program in Genomics of Differentiation, National Institute of Child Health and Human Development, National Institutes of Health, Bethesda, Maryland, USA.

\section{Authors' contributions}

$\mathrm{MH}$ prepared the cultures and carried out most of the experiments and data analysis, and wrote the manuscript. Al carried out RNA isolation and GPCR experiments, and helped development of the expression constructs. DP participated in data interpretation and critical reading of the manuscript. $\mathrm{KO}$ provided anti-IRF8 antibody and participated in data interpretation and critical reading of the manuscript. TI conceived the study, contributed to the experimental design, and helped to write the manuscript. All authors read and approved the final manuscript.

\section{Competing interests}

The authors declare that they have no competing interests.

Received: 9 October 2010 Accepted: 24 January 2011

Published: 24 January 2011

\section{References}

1. Watanabe M, Hadzic T, Nishiyama A: Transient upregulation of Nkx2.2 expression in oligodendrocyte lineage cells during remyelination. Glia 2004, 46:311-322.

2. Islam MS, Tatsumi K, Okuda H, Shiosaka S, Wanaka A: Olig2-expressing progenitor cells preferentially differentiate into oligodendrocytes in cuprizone-induced demyelinated lesions. Neurochem Int 2009, 54:192-198.

3. Reynolds R, Dawson M, Papadopoulos D, Polito A, Di Bello IC, PhamDinh D, Levine J: The response of NG2-expressing oligodendrocyte progenitors to demyelination in MOG-EAE and MS. J Neurocytol 2002, 31:523-536.

4. Agresti C, D'Urso D, Levi G: Reversible inhibitory effects of interferongamma and tumour necrosis factor-alpha on oligodendroglial lineage cell proliferation and differentiation in vitro. Eur J Neurosci 1996, 8:1106-1116

5. Andrews T, Zhang P, Bhat NR: TNFalpha potentiates IFNgamma-induced cell death in oligodendrocyte progenitors. J Neurosci Res 1998, 54:574-583.

6. Balabanov R, Strand K, Kemper A, Lee JY, Popko B: Suppressor of cytokine signaling 1 expression protects oligodendrocytes from the deleterious effects of interferon-gamma. J Neurosci 2006, 26:5143-5152.

7. Chew LJ, King WC, Kennedy A, Gallo V: Interferon-gamma inhibits cell cycle exit in differentiating oligodendrocyte progenitor cells. Glia 2005, 52:127-143 
8. Lin W, Harding HP, Ron D, Popko B: Endoplasmic reticulum stress modulates the response of myelinating oligodendrocytes to the immune cytokine interferon-gamma. J Cell Biol 2005, 169:603-612.

9. Vartanian T, Li Y, Zhao M, Stefansson K: Interferon-gamma-induced oligodendrocyte cell death: implications for the pathogenesis of multiple sclerosis. Mol Med 1995, 1:732-743

10. Horiuchi $M$, Itoh $A$, Pleasure $D$, Itoh T: MEK-ERK signaling is involved in interferon-gamma-induced death of oligodendroglial progenitor cells. $J$ Biol Chem 2006, 281:20095-20106.

11. Clerico M, Rivoiro C, Contessa G, Viglietti D, Durelli L: The therapy of multiple sclerosis with immune-modulating or immunosuppressive drug. A critical evaluation based upon evidence based parameters and published systematic reviews. Clinical neurology and neurosurgery 2008, 110:878-885.

12. Halfpenny CA, Scolding NJ: Immune-modifying agents do not impair the survival, migration or proliferation of oligodendrocyte progenitors (CG-4) in vitro. J Neuroimmunol 2003, 139:9-16.

13. Heine S, Ebnet J, Maysami S, Stangel M: Effects of interferon-beta on oligodendroglial cells. J Neuroimmunol 2006, 177:173-180.

14. Trebst C, Heine S, Lienenklaus S, Lindner M, Baumgartner W, Weiss S, Stangel M: Lack of interferon-beta leads to accelerated remyelination in a toxic model of central nervous system demyelination. Acta Neuropathol 2007, 114:587-596.

15. Platanias LC: Mechanisms of type-I- and type-II-interferon-mediated signalling. Nat Rev Immunol 2005, 5:375-386

16. Boehm U, Klamp T, Groot M, Howard JC: Cellular responses to interferongamma. Annu Rev Immunol 1997, 15:749-795.

17. Itoh T, Horiuchi M, Itoh A: Interferon-triggered transcriptional cascades in the oligodendroglial lineage: a comparison of induction of MHC class II antigen between oligodendroglial progenitor cells and mature oligodendrocytes. J Neuroimmunol 2009, 212:53-64.

18. Wang Y, Ren Z, Tao D, Tilwalli S, Goswami R, Balabanov R: STAT1/IRF-1 signaling pathway mediates the injurious effect of interferon-gamma on oligodendrocyte progenitor cells. Glia 2010, 58:195-208.

19. Harada H, Fujita T, Miyamoto M, Kimura Y, Maruyama M, Furia A, Miyata T, Taniguchi T: Structurally similar but functionally distinct factors, IRF-1 and IRF-2, bind to the same regulatory elements of IFN and IFNinducible genes. Cell 1989, 58:729-739.

20. Miyamoto M, Fujita T, Kimura Y, Maruyama M, Harada H, Sudo Y, Miyata T, Taniguchi T: Regulated expression of a gene encoding a nuclear factor, IRF-1, that specifically binds to IFN-beta gene regulatory elements. Cell 1988, 54:903-913.

21. Taniguchi T, Ogasawara K, Takaoka A, Tanaka N: IRF family of transcription factors as regulators of host defense. Annu Rev Immunol 2001, 19:623-655.

22. Honda K, Taniguchi T: IRFs: master regulators of signalling by Toll-like receptors and cytosolic pattern-recognition receptors. Nat Rev Immunol 2006, 6:644-658

23. Ozato $K$, Tailor $P$, Kubota $T$ : The interferon regulatory factor family in host defense: mechanism of action. J Biol Chem 2007, 282:20065-20069.

24. Tamura T, Yanai $H$, Savitsky D, Taniguchi T: The IRF family transcription factors in immunity and oncogenesis. Annu Rev Immunol 2008, 26:535-584.

25. Fujii $Y$, Shimizu T, Kusumoto M, Kyogoku Y, Taniguchi T, Hakoshima T: Crystal structure of an IRF-DNA complex reveals novel DNA recognition and cooperative binding to a tandem repeat of core sequences. EMBO J 1999, 18:5028-5041.

26. Harada H, Willison K, Sakakibara J, Miyamoto M, Fujita T, Taniguchi T: Absence of the type I IFN system in EC cells: transcriptional activator (IRF-1) and repressor (IRF-2) genes are developmentally regulated. Cell 1990, 63:303-312.

27. Harada H, Kitagawa M, Tanaka N, Yamamoto H, Harada K, Ishihara M, Taniguchi T: Anti-oncogenic and oncogenic potentials of interferon regulatory factors-1 and -2 . Science 1993, 259:971-974.

28. Agresti C, Bernardo A, Del Russo N, Marziali G, Battistini A, Aloisi F, Levi G, Coccia EM: Synergistic stimulation of MHC class I and IRF-1 gene expression by IFN-gamma and TNF-alpha in oligodendrocytes. Eur J Neurosci 1998, 10:2975-2983.

29. Itoh T, Beesley J, Itoh A, Cohen AS, Kavanaugh B, Coulter DA, Grinspan JB, Pleasure D: AMPA glutamate receptor-mediated calcium signaling is transiently enhanced during development of oligodendrocytes. $J$ Neurochem 2002, 81:390-402.
30. Moran J, Itoh T, Reddy UR, Chen M, Alnemri ES, Pleasure D: Caspase-3 expression by cerebellar granule neurons is regulated by calcium and cyclic AMP. J Neurochem 1999, 73:568-577.

31. Kawanokuchi J, Mizuno T, Kato H, Mitsuma N, Suzumura A: Effects of interferon-beta on microglial functions as inflammatory and antigen presenting cells in the central nervous system. Neuropharmacology 2004, 46:734-742.

32. Vitale G, van Koetsveld PM, de Herder WW, van der Wansem K, Janssen JA, Colao A, Lombardi G, Lamberts SW, Hofland L: Effects of type I interferons on IGF-mediated autocrine/paracrine growth of human neuroendocrine tumor cells. Am J Physiol Endocrinol Metab 2009, 296: E559-566.

33. Meager A: Quantification of interferons by anti-viral assays and their standardization. In Lymphokines and Interferons-A Practical Approach. Edited by: Clemens MJ, Morris AG, Gearing AJH. Oxford: IRL; 1987:129-147.

34. Holohan C, Szegezdi E, Ritter T, O’Brien T, Samali A: Cytokine-induced betacell apoptosis is NO-dependent, mitochondria-mediated and inhibited by BCL-XL. J Cell Mol Med 2008, 12:591-606.

35. Panaretakis T, Hjortsberg L, Tamm KP, Björklund AC, Joseph B, Grandér D: Interferon alpha induces nucleus-independent apoptosis by activating extracellular signal-regulated kinase $1 / 2$ and c-Jun $\mathrm{NH} 2$-terminal kinase downstream of phosphatidylinositol 3-kinase and mammalian target of rapamycin. Mol Biol Cell 2008, 19:41-50.

36. Sharf R, Meraro D, Azriel A, Thornton AM, Ozato K, Petricoin EF, Larner AC, Schaper F, Hauser H, Levi BZ: Phosphorylation events modulate the ability of interferon consensus sequence binding protein to interact with interferon regulatory factors and to bind DNA. J Biol Chem 1997, 272:9785-9792.

37. Bovolenta C, Driggers PH, Marks MS, Medin JA, Politis AD, Vogel SN, Levy DE, Sakaguchi K, Appella E, Coligan JE: Molecular interactions between interferon consensus sequence binding protein and members of the interferon regulatory factor family. Proc Natl Acad Sci USA 1994, 91:5046-5050.

38. Au WC, Pitha PM: Recruitment of multiple interferon regulatory factors and histone acetyltransferase to the transcriptionally active interferon a promoters. J Biol Chem 2001, 276:41629-41637.

39. Ling PD, Warren MK, Vogel SN: Antagonistic effect of interferon-beta on the interferon-gamma-induced expression of la antigen in murine macrophages. J Immunol 1985, 135:1857-1863.

40. Inaba K, Kitaura M, Kato T, Watanabe Y, Kawade Y, Muramatsu S: Contrasting effect of alpha/beta- and gamma-interferons on expression of macrophage la antigens. J Exp Med 1986, 163:1030-1035.

41. Satoh J, Paty DW, Kim SU: Differential effects of beta and gamma interferons on expression of major histocompatibility complex antigens and intercellular adhesion molecule- 1 in cultured fetal human astrocytes. Neurology 1995, 45:367-373.

42. Ransohoff RM, Devajyothi C, Estes ML, Babcock G, Rudick RA, Frohman EM Barna BP: Interferon-beta specifically inhibits interferon-gamma-induced class II major histocompatibility complex gene transcription in a human astrocytoma cell line. J Neuroimmunol 1991, 33:103-112.

43. Lu HT, Riley JL, Babcock GT, Huston M, Stark GR, Boss JM, Ransohoff RM: Interferon (IFN) beta acts downstream of IFN-gamma-induced class II transactivator messenger RNA accumulation to block major histocompatibility complex class II gene expression and requires the 48kD DNA-binding protein, ISGF3-gamma. J Exp Med 1995, 182:1517-1525.

44. Prinz M, Schmidt H, Mildner A, Knobeloch KP, Hanisch UK, Raasch J, Merkler D, Detje C, Gutcher I, Mages J, Lang R, Martin R, Gold R, Becher B, Brück, Kalinke U: Distinct and nonredundant in vivo functions of IFNAR on myeloid cells limit autoimmunity in the central nervous system. Immunity 2008, 28:675-686.

45. Yen $J H$, Ganea D: Interferon beta induces mature dendritic cell apoptosis through caspase-11/caspase-3 activation. Blood 2009, 114:1344-1354

46. Durelli L, Conti L, Clerico M, Boselli D, Contessa G, Ripellino P, Ferrero B, Eid P, Novelli F: T-helper 17 cells expand in multiple sclerosis and are inhibited by interferon-beta. Ann Neurol 2009, 65:499-509.

47. Driggers PH, Ennist DL, Gleason SL, Mak WH, Marks MS, Levi BZ, Flanagan JR, Appella E, Ozato K: An interferon gamma-regulated protein that binds the interferon-inducible enhancer element of major histocompatibility complex class I genes. Proc Natl Acad Sci USA 1990, 87:3743-3747. 
48. Tamura T, Ozato K: ICSBP/IRF-8: its regulatory roles in the development of myeloid cells. J Interferon Cytokine Res 2002, 22:145-152.

49. Wang IM, Contursi C, Masumi A, Ma X, Trinchieri G, Ozato K: An IFNgamma-inducible transcription factor, IFN consensus sequence binding protein (ICSBP), stimulates IL-12 p40 expression in macrophages. $J$ Immunol 2000, 165:271-279.

50. Liu J, Guan X, Tamura T, Ozato K, Ma X: Synergistic activation of interleukin-12 p35 gene transcription by interferon regulatory factor-1 and interferon consensus sequence-binding protein. J Biol Chem 2004, 279:55609-55617.

51. Xiong H, Zhu C, Li H, Chen F, Mayer L, Ozato K, Unkeless JC, Plevy SE: Complex formation of the interferon (IFN) consensus sequence-binding protein with IRF-1 is essential for murine macrophage IFN-gammainduced iNOS gene expression. J Biol Chem 2003, 278:2271-2277.

52. Contursi C, Wang IM, Gabriele L, Gadina M, O'Shea J, Morse HC, Ozato K: IFN consensus sequence binding protein potentiates STAT1-dependent activation of IFNgamma-responsive promoters in macrophages. Proc Natl Acad Sci USA 2000, 97:91-96.

53. Holtschke T, Löhler J, Kanno Y, Fehr T, Giese N, Rosenbauer F, Lou J, Knobeloch KP, Gabriele L, Waring JF, Bachmann MF, Zinkemagel RM, Morse HC, Ozato K, Horak I: Immunodeficiency and chronic myelogenous leukemia-like syndrome in mice with a targeted mutation of the ICSBP gene. Cell 1996, 87:307-317.

54. Scheller M, Foerster J, Heyworth CM, Waring JF, Lohler J, Gilmore GL, Shadduck RK, Dexter TM, Horak I: Altered development and cytokine responses of myeloid progenitors in the absence of transcription factor, interferon consensus sequence binding protein. Blood 1999, 94:3764-3771.

55. Huang W, Zhu C, Wang H, Horvath E, Eklund EA: The interferon consensus sequence-binding protein (ICSBP/IRF8) represses PTPN13 gene transcription in differentiating myeloid cells. J Biol Chem 2008, 283:7921-7935.

56. Gabriele L, Phung J, Fukumoto J, Segal D, Wang IM, Giannakakou P, Giese NA, Ozato K, Morse HC: Regulation of apoptosis in myeloid cells by interferon consensus sequence-binding protein. J Exp Med 1999, 190:411-421.

57. Liu K, Abrams Sl: Coordinate regulation of IFN consensus sequencebinding protein and caspase-1 in the sensitization of human colon carcinoma cells to Fas-mediated apoptosis by IFN-gamma. J Immunol 2003, 170:6329-6337.

58. Kirchhoff $\mathrm{S}$, Hauser $\mathrm{H}$ : Cooperative activity between HER oncogenes and the tumor suppressor IRF-1 results in apoptosis. Oncogene 1999, 18:3725-3736.

59. Mebratu YA, Dickey BF, Evans C, Tesfaigzi Y: The BH3-only protein Bik/Blk/ Nbk inhibits nuclear translocation of activated ERK $1 / 2$ to mediate IFNgamma-induced cell death. J Cell Biol 2008, 183:429-439.

doi:10.1186/1742-2094-8-8

Cite this article as: Horiuchi et al:: Cooperative contributions of Interferon regulatory factor 1 (IRF1) and IRF8 to interferon- $\gamma$-mediated cytotoxic effects on oligodendroglial progenitor cells. Journal of Neuroinflammation 2011 8:8.

\section{Submit your next manuscript to BioMed Central and take full advantage of:}

- Convenient online submission

- Thorough peer review

- No space constraints or color figure charges

- Immediate publication on acceptance

- Inclusion in PubMed, CAS, Scopus and Google Scholar

- Research which is freely available for redistribution

Submit your manuscript at www.biomedcentral.com/submit
Biomed Central 